\section{MODELING OF COMPACT LOOP ANTENNAS}

F. W. Baity

Oak Ridge National Lahoratory, Oak Ridge, TN 37831
CONF-870570--4

DE87 009507

\title{
ABSTRACT
}

A general compact loop antenna model which treats all elements of the anterna as lossy transmission lines has been developed. In addition to capacitively-tuned resonant double loop (RDL) antennas the model treats stub-tuned resonant double loop antennas. Calculations using the model have been compared with measurements on full-scale mockups of resonant double loop antennas for ATF and TFTR in order to refine the transmission line parameters. Results from the model are presented for RDL antenna designs for ATF, TFTR, Tore Supra, and for the Compact Ignition Tokamak (CIT).

\section{INTRODUCTON}

Compact loop antennas in a variety of configurations are being planned for ICRF heating on present and future fusion experiments, including the Compact Ignition Tckamak. Compact loop antennas, in particular the resonant double loop, are capable of operation over a wide frequency range at high if power levels, can be moved relative to the plasma, and require no external impedance matching. In order to predict the performance of the antennas under a variety of operating conditions, over as large as a 3:1 frequency range, accurate models are required. The model described in this paper is able to predict the performance of antennas over the full frequency and load range of interest. The model is thus usable for determining the optimum position of the input coaxial feed and for determining the actual capacitance (or stub length) range needed for a specific application.

\section{DESCRIPIION OF THE CIRCUIT}

A schematic diagram of the circuit used in the model is shown in Fig. 1. The configuration shown is that of a resonant double loop with capacitor tuning, ${ }^{1}$ the configuration for the ATF, TFTR, and Tore Supra designs. Rf power is fed to the antenna through an arrangement consisting of a gas break of arbitrary impedance, a fixed stub for cooling fluid input, and an impedance matched vacuum feed-through. Any of these components can be omitted from the calculation, if desired. The antenna current strap is tapped at some intermediate point along its length by means of a lowinductance connection, where $\alpha$ represents the fraction of total current strap length from one end of the strap. A dielectric disk at the end of the vacuum feed coax is included which serves the dual purpose of providing partial mechanical support for the current strap and of canceling most of the effect of the feed inductance. The current strap is connected to the tuning capacitors, designated $\mathrm{Cl}$ and $\mathrm{C2}$ in Fig. 1, by short transmission line segments. Each variable capacitor also has an inductance, designated LC1 and LC2 in the figure, associated with it which is not negligible for the designs considered. The option of replacing the tuning capacitors with shorted stubs has been provided. Stub tuning looks attractive for CIT and for high frequency operation on Tore Supra. Except for the lead inductance and for the tuning capacitors, each element is treated as a lossy transmission line in the model.

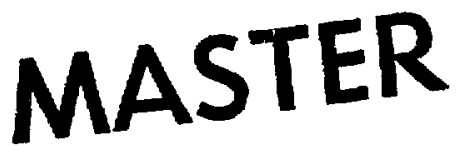

* Research sponsored by the Office of Fusion Energy, U.S. Department of Energy, under contract DE-ACOS-840R21400 with Martin 


\section{Circuit Model}

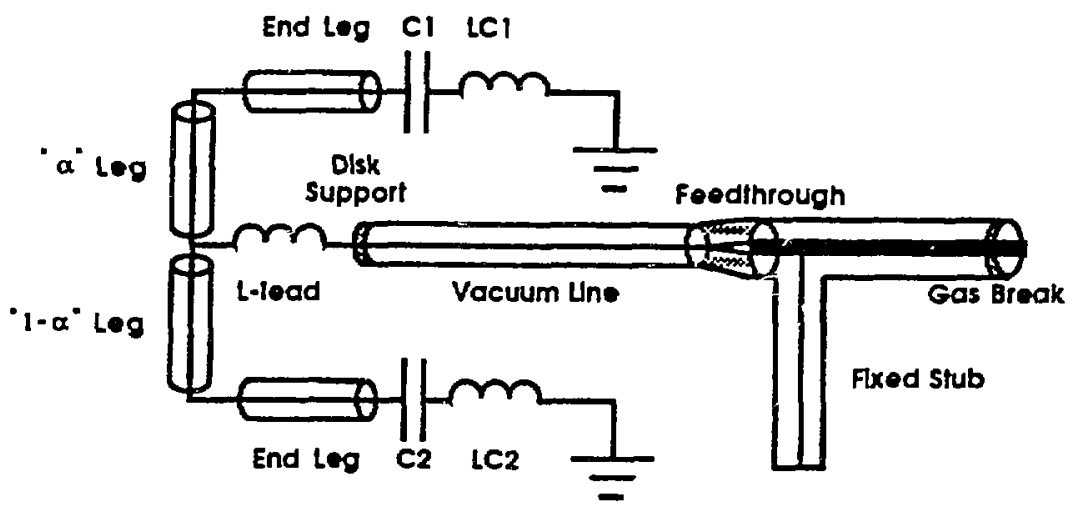

Fig. 1. Schematic diagram of the circuit used in the model.

The two capacitors tune the antenna to the desired frequency and adjust the input impedance to match the transmitter impedance. No additional matching components are required. The effect of the fixed stub can be eliminated over a 3:1 bandwidth by slight retuning of the capacitors.

The model requires the characteristic impedance and phase velocity for each transmission line segment. For the current strap this data can be obtained from 2-D calculations ${ }^{2}$ which include the effect of the Faraday shield or from experimental measurements on a mockup.

The model can be used to calculate the voltage and current distribution along the current strap and tuning elements and the tuning positions required as a function of antenna load resistance. This information is required during the design of an antenna in order to determine the optimum tap position along the current strap for the frequency and load range of operation anticipated, and to determine the power handling capability of the antenna resulting from voltage and current limitations on the various components.

RESULTS

Resonant double loop antennas for fast wave heatin!; have been designed for TFTR $^{3}$ at PPPL, for Tore Supra ${ }^{3}$ at CEN-Cadarache, for ATF at ORNL, and conceptual designs have been studied for CIT. The antennas for TFTR and for Tore Supra have several similarities. Both have two current straps side by side with a common Faraday shield, both are designed to couple $2 \mathrm{MW}$ per loop into the plasma, and both work in about the same frequency range (35 to $80 \mathrm{MHz}$ for Tore Supra). The antenna for the ATF stellarator has a single loop and operates over a lower frequency range ( 10 to $30 \mathrm{MHz}$ ) than TFTR and Tore Supra. The CIT antenna has two current straps stacked end to end in a single port. The design frequency will depend on the final CIT parameters, but should be in the range of 70 to $120 \mathrm{MHz}$.

Current and voltage profiles for the Tore Supra entenna at $35 \mathrm{MHz}$ and at $80 \mathrm{MHz}$ are shown in Figs. 2 and 3, respectively. The plot extends from one capacitor terminal to the other. The dotted vertical line represents the position of the feed line, and the two solid vertical lines are drawn at the ends of the current strap. Both the 
cases plotted are near the minimum loading required to couple $2 \mathrm{MW}$ into the plasma for the frequency under consideration, using capacitor limits of $1 \mathrm{k} A \mathrm{rms}$ current and $50 \mathrm{kV}$ peak voltage. Note that the tap position, $\alpha$, of 0.65 is nearly optimal for loads in this frequency range, resulting in fairly symmetric profiles. The voltage and curyent in the vacuum feed line and fixed stub are shown in Fig. 4 for the $80 \mathrm{MHz}$ case. The fixed stub was chosen to be a quarter wavelength at $57 \mathrm{MHz}$, but the antenna can be matched to the transmitter impedance of $30 \Omega$ over the entire frequency band.

For operation at $120 \mathrm{MHz}$ on Tore Supra the capacitors can be replaced with shorted stubs. The voltage and current profiles on the antenna for this case are shown in Fig. 5, where the plot extends to the shorted end of the stubs. Even at $120 \mathrm{MHz}$ the tap position of 0.65 results in a nearly symmetric waveform on the current strap. For this high frequency operation on Tore Supra the fixed stub must be reduced in length by half. Note that the antenna is nearly one half wavelength long.

For the CIT geometry shown in Fig. 6 capacitor tuning is still feasible up to frequencies greater than $100 \mathrm{MHz}$, but above $100 \mathrm{MHz}$ stub tuning looks more attractive. An example of a capacitor tuned antenna at $100 \mathrm{MHz}$ is shown in Fig. 7 . For a loading of $10 \Omega / \mathrm{m}$ and a maximum capacitor voltage of $50 \mathrm{kV}, 1.3 \mathrm{MW}$ per loop can be achieved. Nevertheless, with higher loading or voltage limits, it would appear that 1.6 MW per loop is a realistic goal for CIT antennas operating near $100 \mathrm{MHz}$.

\section{REFERENCES}

1. T. L. Owens, F. W. Baity, D. J. Hoffman, Radiofrequency Plasma Heating (AIP Conference Proceedings No. 129, N.Y., 1985), p. 95.

2. G. L. Chen, P. M. Ryan, D. J. Hoffman, F. W. Baity, D. W. Swain, J. H. Whealton, "Reșonant Loop Antenna Design with a 2-D Electromagnetic Steady State Analysis," this conference.

3. D. J. Hoffman, F. W. Baity, W. E. Bryan, G. L. Chen, K. H. Luk, T. L. Owens, J. M. Ray, P. M. Ryan, D. W. Swain, J. C. Walls,"The Design of High Power ICRF Antennas for TFTR and Tore Supra," this conference.
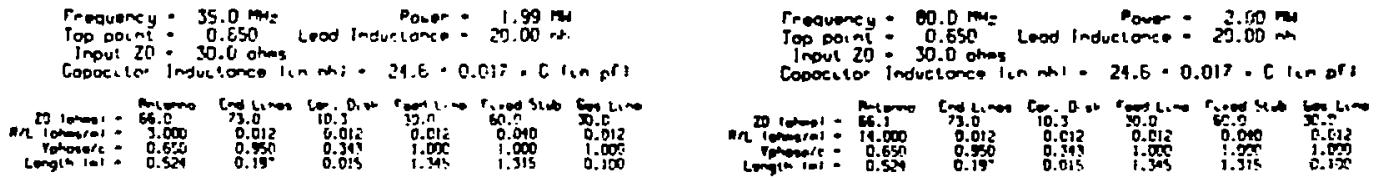

Voltage and Current Profiles

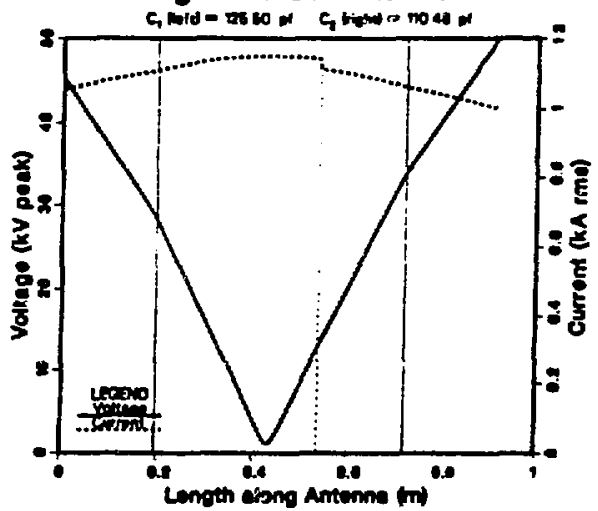

Fig. 2. Current and voltage profiles for the Tore Supra antenna at $35 \mathrm{MHz}$.

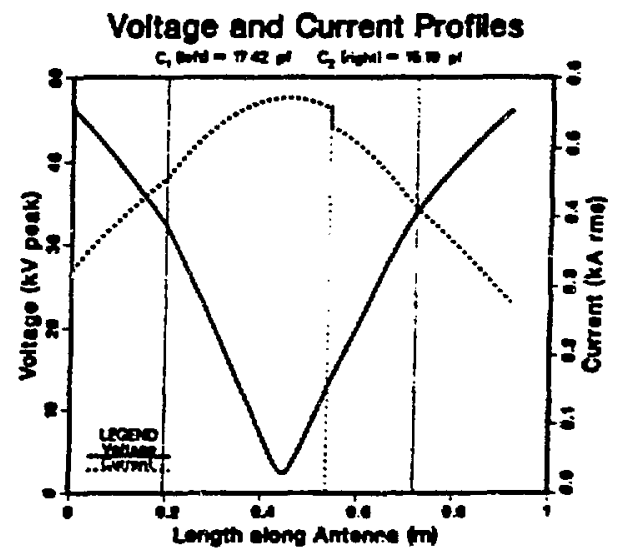

Fig. 3. Current and voltage profiles for the Tore Supra antenna at $80 \mathrm{MHz}$. 


\section{DISCLAIMER}

This report was prepared as an account of work sponsored by an agency of the United States Government. Neither the United States Government nor any agency thereof, nor any of their employees, makes any warranty, express or implied, or assumes any legal liability or responsibility for the accuracy, completeness, or usefulness of any information, apparatus, product, or process disclosed, or represents that its use would not infringe privately owned rights. Reference herein to any specific commercial product, process, or service by trade name, trademark, manufacturer, $r$ otherwise does not necessarily constitute or imply its endorsement, recommendation, or favoring by the United States Government or any agency thereof. The views and opinions of authors expressed herein do not necessarily state or reflect those of the United States Government or any agency thereof. 
Tore Supra ICRF Antenna

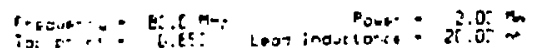

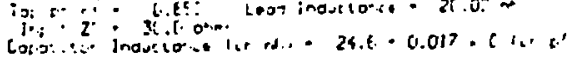

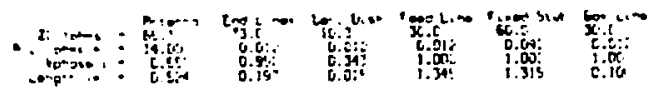

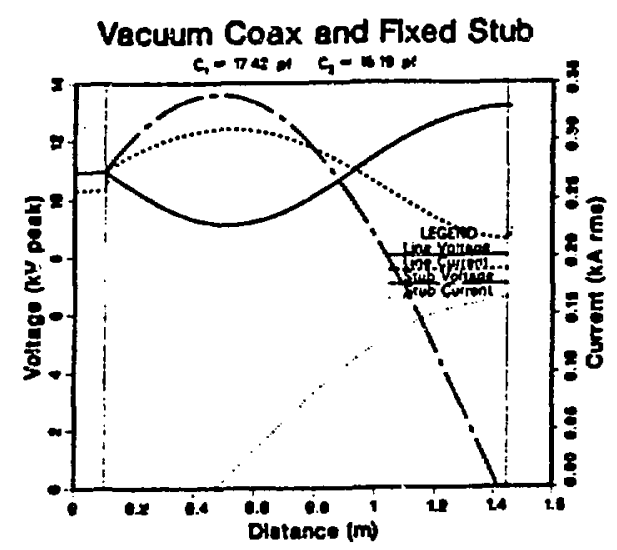

Fig. 4. Current and voltage profiles in the vacuum coax and fixed stub for the Tore Supra antenna at $80 \mathrm{MHz}$.
Tore Suprá ICRF Antenna

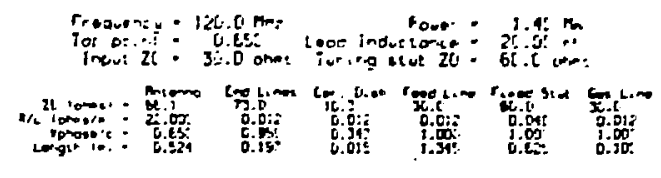

Voltage and Current Protiles

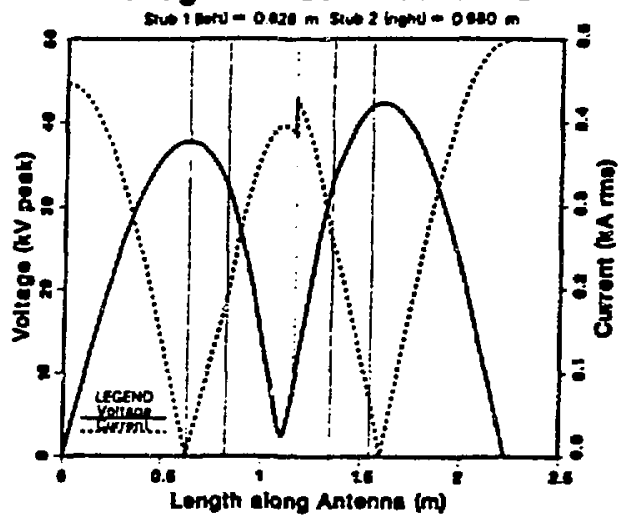

Fig. 5. Current and voltage profiles for the Tore Supra antenna at $120 \mathrm{MHz}$ with stub tuning.

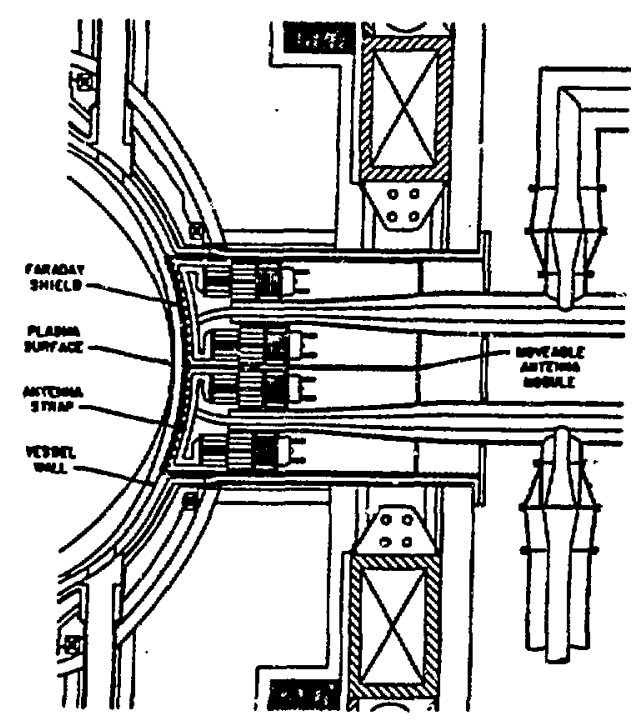

Fig. 6. Conceptual CIT ICRF antenna with capacitor tuning.

\section{CIT ICRF Antenna}

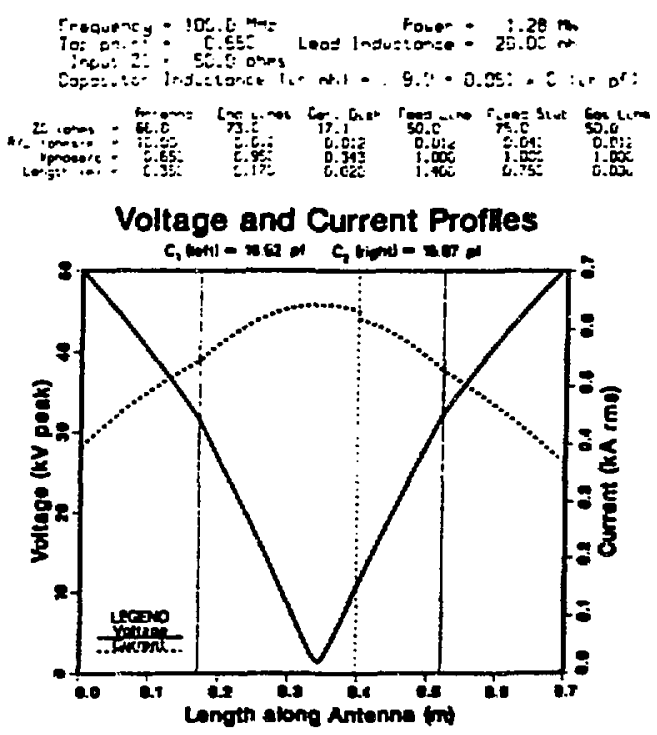

Fig.7. Current and voltage profiles for the CIT antenna at $100 \mathrm{MHz}$. 